\title{
Porous microsphere and its applications
}

\author{
This article was published in the following Dove Press journal: \\ International Journal of Nanomedicine \\ 14 March 2013 \\ Number of times this article has been viewed
}

\section{Yunpeng Cai ${ }^{1,2, *}$ \\ Yinghui Chen ${ }^{3, *}$ \\ Xiaoyun Hong ${ }^{2}$ \\ Zhenguo Liu' \\ Weien Yuan ${ }^{2}$}

'Department of Neurology, Xinhua Hospital affiliated to Shanghai Jiaotong University

School of Medicine, ${ }^{2}$ School of Pharmacy, Shanghai JiaoTong University, ${ }^{3}$ Department of Neurology Jinshan Hospital, Fudan University, Shanghai, People's Republic of China

*These authors contributed equally to this work
Correspondence:Weien Yuan School of Pharmacy, Shanghai Jiao Tong University, 800 Dongchuan Road, Shanghai 200240 ,

People's Republic of China

Tel +86 2l 34205072

Email yuanweien@I26.com

Zhenguo Liu

Department of Neurology, Xinhua Hospital Affiliated To Shanghai Jiao Tong University School of Medicine, I 665

Kongjiang Road, Shanghai 200092, People's

Republic of China

Tel/fax +862165790000

Email zhenguoliu2004@yahoo.com.cn

\begin{abstract}
Porous microspheres have drawn great attention in the last two decades for their potential applications in many fields, such as carriers for drugs, absorption and desorption of substances, pulmonary drug delivery, and tissue regeneration. The application of porous microspheres has become a feasible way to address existing problems. In this essay, we give a brief introduction of the porous microsphere, its characteristics, preparation methods, applications, and a brief summary of existing problems and research tendencies.
\end{abstract}

Keywords: pore, porosity, porogen, suspension polymerization, seed swelling, pulmonary drug delivery, tissue regeneration

\section{Introduction}

Porous microspheres have external pores on the surface or internal pores in the core (usually interconnective), and active substances can be dissolved or dispersed on the surface or in the core of the microspheres. In the 1950s, cross-linked polystyrene with a macroporous structure in the dry state was prepared by a novel polymerization method. ${ }^{1}$ Little progress was made until the 1990s when porous microspheres were identified as suitable materials for potential applications including as carriers for drugs, high speed chromatography, cell delivery, and tissue regeneration as a scaffold. Compared with traditional microspheres, they show many unique properties such as special behavior of drug absorption and drug release kinetics, large specific surface area, and low density.

What differentiates porous microspheres from traditional microspheres are the pores on the surface and inside. Porosity plays an important role in determining the capacity efficiency and release kinetics. The diameter, the amount, and the structure of the pores are the crucial factors affecting the properties of porous microspheres. ${ }^{2}$ Most applications of porous microspheres are based on the porous structure (porosities, pore sizes, surface areas, and so on). To control the pore structure parameters is therefore of particular importance.

\section{Characterization of porous microspheres Size and morphology of porous microspheres}

Porous microsphere morphology can be directly observed with microscopy or scanning electron microscopy (SEM). The diameter of microspheres can be determined by dynamic light scattering. Figure 1 shows typical porous microspheres. 


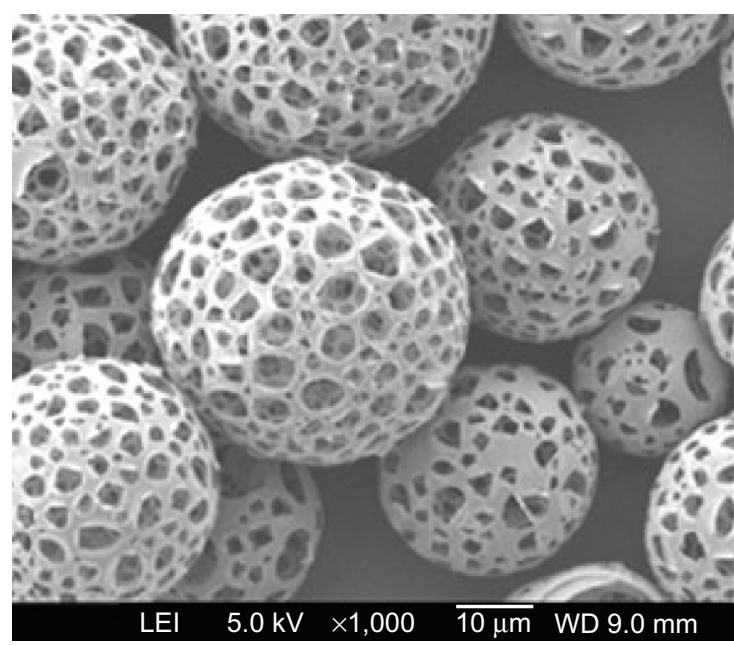

Figure I Porous microspheres.

Note: Springer, Colloid and Polymer Science, 29I, 2013, [page 119], Double emulsiontemplated microspheres with flow-through pores at micrometer scale, Chen SF, Gao F, Wang QB, Su ZG, Ma GH, [Figure 3C], [License Number 30952701 I6326], with kind permission from Springer Science and Business Media. ${ }^{68}$

\section{Pore size of porous microspheres}

Pore size is one of the most important features which influences the application of porous microspheres. Usually pore size can be determined by SEM, transmission electron microscopy (TEM), or confocal laser scanning microscopy (CLSM).

According to the International Union of Pure and Applied Chemistry classification, ${ }^{3}$ porous materials can be classified according to their pore sizes: microporous materials (less than $2 \mathrm{~nm})$, mesoporous materials $(2-50 \mathrm{~nm})$, macroporous materials (50-200 nm), and gigaporous materials (more than $200 \mathrm{~nm}$ ). The diversities in pore sizes meet requirements in many practical applications and are intensively studied for their promising virtues.

The pore size is an important factor in determining the adsorption and release of biomolecules. In the field of enzyme immobilization, many studies have proved that pore size of heterogeneous support is probably the most important parameter and have indicated that the ideal size of the pores is three to five times that of the protein size. ${ }^{4}$

As pore size plays an essential part in the porous microspheres, some efforts have been made to regulate the pore size, but there's still no universal method to deal with this problem. In many studies, pore size was controlled to some degree by choosing suitable porogens or by adjusting their concentrations. Only a few studies have tried to discover a universal technology. Cheng et al employed $\mathrm{CO}_{2}$ bubbles as templates and precisely adjusted the system pressure. ${ }^{5}$ Their carbonated hydroxyapatite microspheres' pore sizes could be well regulated over a wide range from the microscale to the nanoscale. Their results suggested that the gathering and growth of the $\mathrm{CO}_{2}$ bubbles generated the formations of the porous structure, and with the increase of system pressure, the surface of the microsphere got denser and the flakes, which assembled the porous structure, became smaller. ${ }^{5} \mathrm{Li}$ and Zhang developed a new method to produce a porous polymer film with size-tunable pores on its surface. ${ }^{6}$ The porous film was produced using polystyrene microspheres as a template and the surface pore size could be tuned without changing the size of the template microsphere. Polystyrene microspheres were self-assembled on a substrate precoated with a thin layer of polystyrene and heated at an appropriate temperature, prior to infusion of a polymer precursor solution into cavities of the template microspheres, solidification of the polymer, and removal of the microspheres. The surface pore sizes could be tuned by changing the temperature and time for the heat treatment.

\section{Surface area and porosity of porous microspheres}

The specific surface area of porous microspheres can be investigated by nitrogen adsorption/desorption analysis, and a Brunauer-Emmett-Teller absorption model is often adopted. ${ }^{7}$ The porosity equals the ratio of pore volume to total volume, which can be investigated by Barrett-Joyner-Halenda (BJH) measurement. In this method, $\mathrm{N}_{2}$ adsorption-desorption is carried out at $77 \mathrm{~K}$. According to the BJH equation, both the pore size and pore volume can be calculated. ${ }^{8}$ Mercuryintrusion porosimetry is also used to investigate the porosity, in particular for relatively big pore size microspheres. ${ }^{9}$

The porosity and specific surface area have a direct relationship with the microsphere's density (for pulmonary delivery) and drug absorption amount, and a controllable porosity is preferable. Generally, in cases with porogens, porosity can be regulated by carefully adjusting the amount of porogen and the volume of porogen particulates. ${ }^{10}$

\section{Materials for preparing porous microspheres Framework material}

Many materials employed in traditional microspheres can also be employed in preparing porous microspheres. The most commonly employed materials are polymers such as polylactic acid, poly(lactic-co-glycolic acid) (PLGA), chitosan, polycaprolactone (PCL), divinylbenzene, and other polymers or co-polymers.

Besides polymers, some other materials also have some superiority at fabricating porous microspheres, including both organic and inorganic materials such as calcium carbonate $\left(\mathrm{CaCO}_{3}\right)$, mesporous silica, hydroxyapatite, and biodegrad- 
able porous starch foam. ${ }^{11-13}$ These materials have merits like biocompatibility or have a higher porosity or can be easily modified.

\section{Porogen}

Porogen is also called pore-forming agent. In most experiments, it's widely employed to form the pores. Porogens are often used in solvent methods and polymerization methods, which are the most common methods to prepare porous microspheres.

The mechanism of porogens can usually be described as solvent casting/particulate leaching, in which porogen is usually an unreactive agent added into the materials for porous microsphere preparation. Once the porogen particulates are removed, the spaces they leave become the pores both externally and internally. However, the process that requires the porogens to be extracted later causes other problems. The pore-forming strategy involving these porogens has inherent limitations: leaching with solvents facilitates diffusional mass exchange, which removes not only porogens but also encapsulated actives. Moreover, the high-shear inherent in emulsification leads to microspheres with broad distributions in size and morphology and this can be further exacerbated by the inclusion of these porogens. Also, the porogens usually require a long time to leach out completely. ${ }^{14-16}$

Though with some drawbacks, fabricating porous microspheres with a porogen is widely reported. The commonly used porogens are effervescent salts like ammonium bicarbonate, inorganic salts like sodium chloride, hydrocarbon waxes, linear polymers, carbohydrates, gelatin, ice, and sugar. ${ }^{17-19}$

Figure 2 shows how the pores form with porogen. ${ }^{20}$

\section{Methods for preparing porous microspheres Solvent evaporation method}

The most widely used method to fabricate porous microspheres is the solvent evaporation method. Multi-emulsion solvent evaporation is commonly employed for the influx between the internal aqueous phase and external aqueous phase, and this influx forms pores easily. In this typical method, dissolved or dispersed polymer is added into a volatile organic phase, and it

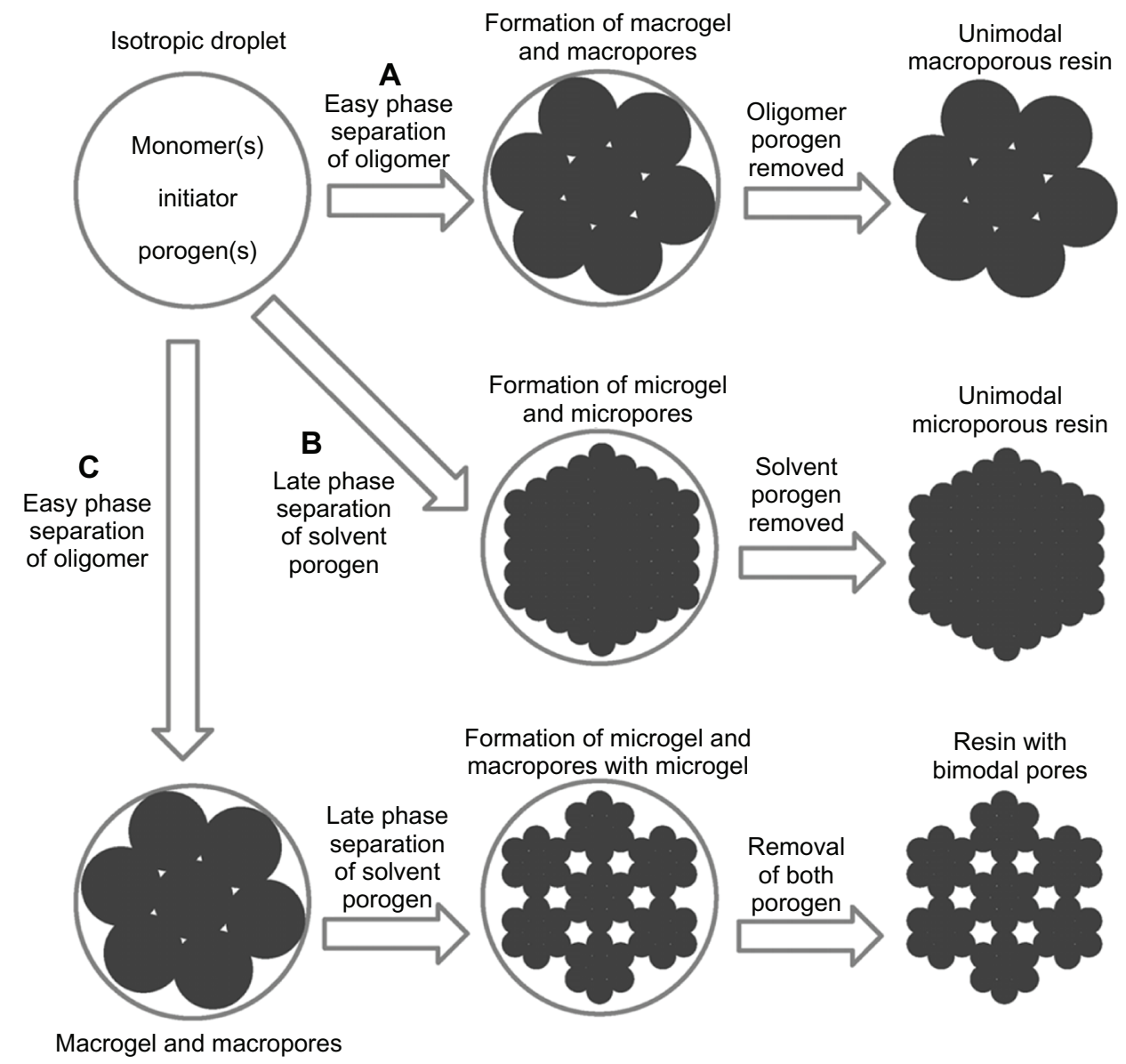

Figure 2 Schematic diagram of pore formation.

Note: Copyright @ 2007, Taylor \& Francis Ltd. Reproduced with permission from Liu QQ, Wang L, Xiao AG. Research progress in macroporous styrene-divinylbenzene co-polymer microspheres. Designed Monomers and Polymers. 2007; 10(5):405-423. ${ }^{20} \mathrm{http}: / / \mathrm{www}$.informaworld.com. 
is emulsified in an aqueous phase with a surfactant. The volatile solvent is removed as it diffuses into the aqueous medium and evaporates at the air/water interface under constant stirring, leaving only spherical polymer microspheres in the aqueous phase. Usually the drug is added in with the polymer, so that the drug is entrapped or imbedded in the polymer.

In this method, the diffusion of the inner phase can contribute to the formation of the pores. But to obtain an optimum porosity, porogens are often employed, which can adjust the porosity and the diameter of the pores more easily. The drawbacks of employing porogens have been discussed above. Another drawback of this method lies in the use of organic solvents which must be fully removed to avoid any possible damage concerning applications in vivo.

It has been reported that in a solid-in-oil-in-water emulsion system, the addition of the solid phase in the system is a key factor in forming the porous structure. The affinity between the solid and oil phases influences the speed of the oil phase diffusion. Results show that high affinity between solid-polymer and polymer-medium, and low affinity between solid-medium are the best combinations to obtain porous microspheres. ${ }^{21}$

A novel type of porous microsphere characterized by a dense core and a porous layer with an assembly of conelike pores was reported. ${ }^{22}$ In the presence of $\mathrm{NaCl}$, particles like hydroxyapatite can work as emulsifiers. Furthermore, hydrophilic particles such as metal oxides tend to stabilize oil-in-water emulsions while hydrophobic particles such as carbon tend to stabilize water-in-oil emulsions. ${ }^{23}$

Large osmotic pressure differentials between the inner and outer aqueous phases can also be used to produce macroporous microspheres, because of the large influx of the inner liquid phase driven by the pressure gradient. Thus the polymer dissolved in the inner aqueous phase is a key to control porosity. The molecule weight and concentration can be controlled to fabricate microspheres with a desired porosity. Owen et al used high molecular weight poly(lactideco-glycolide) at a concentration of $100 \mathrm{mg} / \mathrm{mL}$ in the internal aqueous phase and fabricated macroporous microspheres, with a particle size range of 5-20 $\mu \mathrm{m}$ and pore sizes of $1-5 \mu \mathrm{m} .{ }^{24}$ Furthermore, by altering the inner aqueous volume fraction, extremely different porous and nonporous shell layer morphologies can be modulated. ${ }^{11}$

\section{Polymerization method}

Suspension polymerization, precipitation polymerization, and emulsification polymerization methods are widely adopted to prepare porous microspheres. Sometimes they can be classified as phase separation methods.
In suspension polymerization, the reaction mixture consists of two phases, a liquid matrix and monomer droplets. The monomer and initiator (like crosslinker) are insoluble in the liquid phase, so they form drops within the liquid matrix. A suspension agent is usually added to stabilize the monomer droplets and hinder monomer drops from coming together. Micron-size monodispersed microspheres can be prepared with this method. Jayakrishnan and Thanoo prepared porous beads of poly(2-hydroxyethyl methacrylate) with the suspension polymerization method..$^{25}$

Precipitation polymerization is similar to the suspension polymerization method. The difference lies in the fact that precipitation polymerization gives larger and less regular particles, as a result of little or no stabilizer being present. In this method, the monomer and initiator are soluble, and upon initiation the formed polymer is insoluble and thus microspheres precipitate. Li and Stöver prepared porous poly(divinylbenzene) microspheres with precipitation polymerization, which have diameters between 4-7 $\mu \mathrm{m}$, total pore volumes of up to $0.52 \mathrm{~cm}^{3} / \mathrm{g}$, and surface areas of up to $800 \mathrm{~m}^{2} / \mathrm{g}^{26}$

In emulsification polymerization, an emulsion, monomer, and a surfactant are needed. The most common type of emulsification polymerization is an oil-in-water emulsion, in which droplets of monomer (the oil) are emulsified (with surfactants) in a continuous phase of water. Then the surfactant stabilizes the surface between microspheres and the continuous phase, and the charge of the surfactant stops the coagulation of microspheres. It has been reported that in some cases a surfactant is not required to realize emulsification polymerization. ${ }^{27,28}$ Sometimes an emulsifier is not a must in emulsification polymerization. In an experiment, Okubo et al fabricated a 'golf ball-like' microsphere with many dents on it by seeded emulsion polymerization without an emulsifier. ${ }^{29}$

\section{Seed swelling method}

Monodispersed porous polymer microspheres can be prepared using the seed swelling method. The reaction system consists of seed, monomer, dispersed phase, initiator (crosslinker), and stabilizer.

A seed polymer is employed, which is often prepared by the suspension polymerization method. This seed acts as a template that retains its shape as it is swollen by the entrance of monomers and solvents. However, this procedure is timeconsuming and also difficult to carry out compared with other methods, and the condition of the seed is vital. Some researchers have modified this seed swelling method into two 
steps, which simplifies the process, although the process is still time consuming to prepare well monodispersed porous microspheres. ${ }^{30-32}$

Generally, the seed swelling method can be classified as below:

1. One-step seed swelling method: In this method, seeds are prepared by suspension polymerization. Then in a polymer emulsion, in the presence of a crosslinker, monomers aggregate on the seeds as the seeds 'swell' into microspheres. A porous structure is formed by the separation of porogens (also called diluents), which are added in the suspension polymerization step. However, this method cannot prepare large porous microspheres (diameter above $10 \mu \mathrm{m}){ }^{33,34}$

2. Stepwise seed swelling method: The difference is that the swelling process is repeated many times. Though large microspheres can be prepared, it is rather timeconsuming. ${ }^{31}$

3. Two-step seed swelling method: This method allows an enormous increase of absorption capacity in the swelling step. Thus, microspheres with large size can be prepared. By making the seeds absorb a water insoluble, relatively low molecular weight compound in the first step, the absorption capacity in the second swelling step can be increased. ${ }^{35}$ A similar experiment used acetone as carriers to facilitate the diffusion of monomers into the seeds. ${ }^{36}$

4. Dynamic seed swelling method: This method can also increase the absorption of monomers by simply changing the temperature of the system in the swelling process. Large monodispersed microspheres can be prepared. ${ }^{37}$

\section{Sinter method}

In this method, porous microspheres are fabricated by the bonding of materials, and some materials are burned off under high temperature while the heat-resistant materials are left to form the matrix of microspheres. For example, hydroxyapatite is often used in orthopedic or bone surgery due to its biocompatibility, non-toxicity, and osteoconductivity. Hydroxyapatite is mixed with a chitosan solution, with a surfactant to stabilize the surface and glutaraldehyde to make the microspheres harden under constant stirring. When the microspheres form, they are dried at $60^{\circ} \mathrm{C}$ for 3 hours. These chitosan-bonded spheres are heated initially at $500^{\circ} \mathrm{C}$ for 1 hour to burn off the chitosan and are finally sintered at $1100^{\circ} \mathrm{C}$ for 1 hour, at which point the porous microspheres are completed. The pores consist of the burned-off chitosan in the hydroxyapatite's structure. ${ }^{38}$

\section{Synthesis method}

This method is often seen in preparing mesoporous silica microspheres. Silica and other metal oxides with uniform mesoscale pore channels (typically in the range of 2-10 nm) are usually employed. The uniform pore channels and narrow pore size distribution are ideal properties for porous microspheres. ${ }^{39}$ Usually, inorganic pressure and organic templates are synthesized into mesoporous materials. For a typical synthesis, $\mathrm{BmimBF}_{4}$ is added into a $\mathrm{Na}_{2} \mathrm{SiO}_{3} \cdot 9 \mathrm{H}_{2} \mathrm{O}$ solution, then hydrochloric acid is added, all while under shaking. The mixture is aged for 5 hours at room temperature under quiescent conditions and then transferred into an oven at $80^{\circ} \mathrm{C}$ for another 60 hours. The product is collected by centrifugation and washing with deionized water and ethanol several times. Finally, the solid product is calcined at $550^{\circ} \mathrm{C}$ for 4 hours to remove impurities. ${ }^{40}$ Synthesis with an organic template method in an oil-in-water phase has also been reported. ${ }^{41}$

\section{Phase separation method}

In this method, the first step is usually to prepare a polymer solution with the substances to be encapsulated, and add in other substances or solvents that lower the polymer's solubility, then the polymers which encapsulate the drugs separate in a new condensed phase. The pores form with the solvent diffusion. Mandal et al prepared PLGA porous microspheres with the phase separation method, and got a higher encapsulation rate $(58 \%)$ than the water-in-oil-in-water solvent evaporation method $(16 \%){ }^{42}$

\section{Spray drying method}

In this method, polymers and the substances to be encapsulated are all dissolved or suspended in a liquid. When the liquid is sprayed out by a nozzle, heated air will make the liquid of the drops evaporate, leaving the polymer and substances to form microspheres. Straub et al prepared porous PLGA microspheres by spray drying, which had an average diameter of $2.3 \mu \mathrm{m} .{ }^{43}$ Ammonium bicarbonate was employed as a porogen.

\section{Other methods}

Preparation methods combined with new technologies have also been reported in recent years. For example, with microfluidic techniques, the polydispersity in particle size can be significantly reduced. ${ }^{14}$ With molecular imprinting technology, molecularly imprinted polymers can afford specific recognition against an imprinting molecule and moderate recognition against the structurally-related compounds. ${ }^{44,45}$ 
Baimark prepared porous MPEG-b-PCLDLL microspheres by a melt dispersion method. ${ }^{46}$ Any organic solvents and surfactants can be neglected for this method.

Table 1 provides a summary of the porous microsphere preparation methods discussed here.

\section{Applications of porous microspheres}

\section{Tissue regeneration scaffolds}

Porous microspheres can form a higher structure for versatile applications by methods such as thermally induced phase separation, microsphere sintering, electrospinning, and hydrogelling. In this situation, a highly porous structure with well interconnected pores is required not only to achieve sufficient cell seeding density within the scaffold, but also to facilitate in- and out-transport of nutrients and oxygen for subsequent cell proliferation and differentiation. ${ }^{47}$

The use of three-dimensional porous microspheres as scaffolds in tissue engineering is widely reported. Usually the porous microspheres are heated just above their glass transition temperature to sinter into porous scaffolds. However, it's reported that heat sintering is not applicable across a broad spectrum of polymer types due to its dependence on specific physicochemical properties such as: glass transition temperature, specific heat, crystallinity, viscosity, and surface tension of the polymer to be sintered. ${ }^{48}$

The porous scaffolds take on a porous structure and facilitate the adhesion and proliferation of cells and usually they carry some drugs like cell growth factors to assist the proliferation of cells during tissue regeneration. Both the

Table I Summary of porous microsphere preparation methods

\begin{tabular}{|c|c|c|c|}
\hline & Particle size & Advantages & Disadvantages \\
\hline \multicolumn{4}{|c|}{ Preparation method } \\
\hline $\begin{array}{l}\text { Solvent evaporation } \\
\text { method }\end{array}$ & $0.1-1000 \mu \mathrm{m}$ & Easy to prepare & $\begin{array}{l}\text { Diffusion of internal aqueous phase or } \\
\text { oil phase affects pore size and porosity }\end{array}$ \\
\hline \multicolumn{4}{|c|}{ Polymerization method } \\
\hline $\begin{array}{l}\text { Emulsification } \\
\text { polymerization }\end{array}$ & $100 \mathrm{~nm}$ to $\mathrm{I} \mathrm{mm}$ & $\begin{array}{l}\text { Fast reaction speed; } \\
\text { low viscosity of medium; } \\
\text { narrow size distribution; } \\
\text { controllable reaction temperature }\end{array}$ & Surfactants are difficult to remove \\
\hline $\begin{array}{l}\text { Suspension } \\
\text { polymerization }\end{array}$ & $100 \mathrm{~nm}$ to $5 \mathrm{~mm}$ & $\begin{array}{l}\text { Narrow size distribution; } \\
\text { controllable reaction temperature }\end{array}$ & Suspension agents are difficult to remove \\
\hline $\begin{array}{l}\text { Precipitation } \\
\text { polymerization }\end{array}$ & $100 \mathrm{~nm}$ to $5 \mathrm{~mm}$ & $\begin{array}{l}\text { No suspension agents; } \\
\text { narrow size distribution; } \\
\text { controllable reaction temperature }\end{array}$ & $\begin{array}{l}\text { Relatively larger and less regular } \\
\text { compared with suspension polymerization; } \\
\text { sensitive to reaction condition }\end{array}$ \\
\hline \multicolumn{4}{|c|}{ Seed swelling method } \\
\hline $\begin{array}{l}\text { One step seed } \\
\text { swelling }\end{array}$ & $0.1-10 \mu \mathrm{m}$ & Monodispersity & $\begin{array}{l}\text { Cannot prepare large porous } \\
\text { microspheres over } 10 \mu \mathrm{m} ; \\
\text { time consuming }\end{array}$ \\
\hline $\begin{array}{l}\text { Stepwise seed } \\
\text { swelling method }\end{array}$ & $\mathrm{I}-\mathrm{I} 00 \mu \mathrm{m}$ & $\begin{array}{l}\text { Monodispersity; } \\
\text { larger size compared to } \\
\text { one step seed swelling }\end{array}$ & $\begin{array}{l}\text { Time consuming; } \\
\text { complicated }\end{array}$ \\
\hline $\begin{array}{l}\text { Two-step seed } \\
\text { swelling method }\end{array}$ & $\mathrm{I}-\mathrm{I} 00 \mu \mathrm{m}$ & $\begin{array}{l}\text { Monodispersity; } \\
\text { larger size compared to } \\
\text { one step seed swelling }\end{array}$ & $\begin{array}{l}\text { Complicated; } \\
\text { time consuming }\end{array}$ \\
\hline $\begin{array}{l}\text { Dynamic seed } \\
\text { swelling method }\end{array}$ & $\mathrm{I}-\mathrm{I} 00 \mu \mathrm{m}$ & $\begin{array}{l}\text { Monodispersity; simpler than } \\
\text { two-step seed swelling }\end{array}$ & Time consuming \\
\hline $\begin{array}{l}\text { Phase separation } \\
\text { method }\end{array}$ & $\mathrm{I}-1000 \mu \mathrm{m}$ & Easy & $\begin{array}{l}\text { Sensitive to reaction conditions; } \\
\text { poor monodispersity }\end{array}$ \\
\hline $\begin{array}{l}\text { Spray-drying } \\
\text { method }\end{array}$ & $10-1000 \mu \mathrm{m}$ & Suitable for industry; easy & $\begin{array}{l}\text { Not many ways to form a porous } \\
\text { structure and control the pore size; } \\
\text { not fit for heat-sensitive substances }\end{array}$ \\
\hline Sinter method & $0.1-1000 \mu \mathrm{m}$ & $\begin{array}{l}\text { Porous microspheres can be sintered } \\
\text { into a three-dimensional scaffold with } \\
\text { a controllable porosity and pore size }\end{array}$ & $\begin{array}{l}\text { Not fit for heat-sensitive substances; } \\
\text { microspheres' adhesion during sinter } \\
\text { process }\end{array}$ \\
\hline Synthesis method & $0.1-1000 \mu \mathrm{m}$ & $\begin{array}{l}\text { Uniform pore channels and narrow } \\
\text { pore size distribution }\end{array}$ & $\begin{array}{l}\text { Here synthesis method only refers to } \\
\text { mesoporous microspheres preparation; } \\
\text { complicated }\end{array}$ \\
\hline
\end{tabular}


pores between the microspheres and the smaller pores on the microspheres' surface offer room for the vessels and cells ingrowth. ${ }^{49,50}$

The sinter method is the most frequently used method to prepare a porous microsphere scaffold. However, the best pore parameters for tissue engineering are different depending on what the tissue is. For example, to enhance osteogenic signal expression and support new bone formation, a scaffold's best parameters are not fixed (see Table 2). ${ }^{51}$

Table 2 provides a comparison of the effects of porosity and pore size on osteogenic signal expression and differentiation. ${ }^{52-61}$

Table 2 The effect of porosity and pore size on osteogenic signal expression and differentiation

\begin{tabular}{|c|c|}
\hline Scaffold materials & $\begin{array}{l}\text { Pore parameters' effects } \\
\text { on tissue engineering }\end{array}$ \\
\hline Collagen-GAG & $\begin{array}{l}\text { Chondrocytes synthesized more GAG in } \\
\text { a } 20 \mu \mathrm{m} \text { pore than a } 85 \mu \mathrm{m} \text { pore. } \\
\text { Improved migration in pore sizes } \\
\text { larger than } 300 \mu \mathrm{m} \text {. }\end{array}$ \\
\hline Calcium phosphate & $\begin{array}{l}\text { Higher pore sizes }(280 \mu \mathrm{m}) \text { resulted } \\
\text { in greater osseointegration. Pore size } \\
\text { also affected blood vessel formation. } \\
\text { Bone growth was affected more by pore } \\
\text { size than porosity. Larger pore size } \\
\text { induced greater bone formation. }\end{array}$ \\
\hline$\beta$-TCP & $\begin{array}{l}\text { ALP expression was affected by size } \\
\text { of pores and porosity of scaffolds. Higher } \\
\text { mineralization with higher porosity. }\end{array}$ \\
\hline PLGA & $\begin{array}{l}\text { I00 } \mu \mathrm{m} \text { solid groups had significantly greater } \\
\text { percentage of bone ingrowth compared } \\
\text { with } 500 \mu \mathrm{m} \text { hollow groups of new bone } \\
\text { formation in a cranial defect. }\end{array}$ \\
\hline Polycaprolactone & $\begin{array}{l}\text { Pore sizes between } 350 \mu \mathrm{m} \text { and } 800 \mu \mathrm{m} \\
\text { had limited roles in bone regeneration after } \\
8 \text { weeks of implantation subcutaneously } \\
\text { in mice. } \\
\text { The scaffold section with } 380-405 \mu \mathrm{m} \\
\text { pore size showed better cell growth for } \\
\text { chondrocytes and osteoblasts, while the } \\
186-200 \mu \mathrm{m} \text { pore size was better for } \\
\text { fibroblasts growth. The } 290-310 \mu \mathrm{m} \text { pore } \\
\text { size showed faster new bone formation. }\end{array}$ \\
\hline EH-PEG & $\begin{array}{l}\text { The } 100 \mu \mathrm{m} \text { group had a faster rate of ALP } \\
\text { (alkaline phosphatase, an early marker for } \\
\text { osteoblastic differentiation) expression } \\
\text { compared with the } 250 \mu \mathrm{m} \text { group. }\end{array}$ \\
\hline $\mathrm{HA}$ & $\begin{array}{l}\text { Higher ALP expression of human MSCs } \\
\text { in smaller pore sizes }(200 \mu \mathrm{m}) \text {. } \\
\text { Higher proliferation in larger } \\
\text { pore sizes }(500 \mu \mathrm{m}) \text {. }\end{array}$ \\
\hline
\end{tabular}

Note: Data from. ${ }^{52-61}$

Abbreviations: $\beta$-TCP, beta tricalcium phosphate; ALP, alkaline phosphatase; EH-PEG, 5-ethyl-5-(hydroxymethyl)-beta,beta-dimethyl-1,3-dioxane-2-ethanol-co-polyethylene glycol; GAG, glycosaminoglycan; HA, hydroxyapatite; MSC, mesenchymal stem cell; PLGA, poly(lactic-co-glycolic acid).

\section{High-speed protein chromatography}

Due to the huge specific surface area, porous microspheres are fit for adsorption and desorption substances. Thus a separation of substances can be realized. Many studies have indicated that porous microspheres could be used for highperformance protein chromatography with high column efficiency, high dynamic capacity, and low flow resistance due to their porous nature. During chromatography, the mobile phase can flow through the macropores or the superpores in the solid phases, thus leading to the enhancement of mass transport rate of solute in the materials. On the other hand, the micropores connecting the macropores or superpores provide a large surface area for solute binding. ${ }^{52}$ Employing novel porous microspheres, an efficient low-pressure preparative chromatography for purification of icariin from crude extract has been developed. The microspheres column even demonstrated a higher resolution and better selectivity than the $\mathrm{C} 18$ column. ${ }^{53}$

The porous microspheres applied in chromatography have a size range of $5-10 \mu \mathrm{m}$, and a high porosity is preferred while keeping rigid. Generally, the macropores among the microspheres are $600-800 \mathrm{~nm}$, and the micropores on the porous microspheres are 80-150 nm. Keeping the micropores' depth under $1000 \mathrm{~nm}$ can provide a high separation speed. ${ }^{54}$

\section{Carriers for biomacromolecules or other substances}

Carriers loaded with biomacromolecules have potential applications in tissue engineering, drug delivery, and cell therapy. Biomacromolecules here often refer to proteins, peptides, and genes. These molecules can be absorbed by porous structures due to the large specific surface area, with which a high drug loading amount can be achieved.

The mechanism of the absorption process can be divided into physical and chemical mechanisms. The physical absorption is a weak interaction and usually reversibly driven by a hydrophobic interaction or hydrogen bond. In most cases, we have to take desorption into consideration, so that physical absorption is a better choice. The chemical absorption by contrast is a strong interaction which usually involves chemical reactions, and covalent bonds or ionic bonds form after the chemical reaction.

The pore size plays an essential role in the molecules' absorption and desorption as mentioned before. Li et al investigated how the pore size affects the lipase distribution, thermal stability, storage stability, and reusability. ${ }^{55}$ Their results showed that the thermal stability, storage stability, and reusability were all improved significantly with increased 
pore sizes; while Michaelis constant values were lower in large pore size microspheres.

To achieve better absorption and desorption results, modifying the materials like polymers is often adopted. Wang et al modified polymers with polyethylene glycol; their results showed excellent adsorption and desorption properties with bovine serum albumin and trypsin. ${ }^{56}$

Porous microspheres can provide a high loading efficiency and a good release behavior. However, one of the biggest problems is how to keep the bioactivity of biomolecules. Some researchers have worked on this in recent years. One key factor is to protect the biomacromolecules from the changeable environment. A mild environment can be achieved by coating the biomacromolecules with friendly excipients or entrapping them with $\mathrm{pH}$ buffers or by other means. Furthermore, the use of porogens should also be carefully taken into consideration to avoid inactivation of proteins. An example is that the use of salts, such as calcium and sodium chloride, in the internal water phase has been reported to induce this process and enable the formation of highly porous particles. The use of this formulation strategy, however, can be dangerous due to the fact that salts can cause protein precipitation/aggregation/inactivation as a function of salt type and concentration used. ${ }^{57}$

Kim et al fabricated a pore-closing porous PLGA microsphere, loaded with recombinant human growth hormone (rhGH) ${ }^{58}$ For their controlled release, porous microspheres containing rhGH were treated with water-miscible solvents in an aqueous phase for the production of pore-closed microspheres, and this process was performed in an ethanol vapor phase using a fluidized bed reactor. The results exhibited a high protein loading amount.

As to carrying other substances, such as metals or compounds, porous microspheres can be employed as carriers for catalysts. Porous microspheres with active molecules or active groups can be an excellent catalyst carrier. The larger specific surface area means more active sites for catalyst. So a high porosity is usually preferred. Thus combining catalysts with porous microspheres is a promising method.

Lee et al prepared porous structured $\mathrm{TiO}_{2}$ microspheres, which showed better photocatalytic degradation of phenol compared with $\mathrm{P} 25 \mathrm{TiO}_{2} \cdot{ }^{59}$ Molvinger et al prepared porous chitosan-silica hybrid microspheres as a potential catalyst. ${ }^{60}$

\section{Pulmonary drug delivery}

In recent years, the lung has gained much attention as a noninvasive alternative for protein delivery; biomacromolecules can be absorbed efficiently in a lung surface area of approximately $100 \mathrm{~m}^{2}$, crossing the thin pulmonary absorption barrier. ${ }^{61}$ Here porous microspheres can be adopted as the biomacromolecule vehicle due to their low density of porous structure. Making the porous microspheres into an inhalable aerosol, biomolecules like proteins can be free from first-pass effects and realize a sustained-release. As to pulmonary drug delivery, it is very important to control the diameter of the microspheres and a narrow diameter distribution is preferred. For high deposition of inhaled proteins throughout the lung, the porous microspheres' aerodynamic diameter should be about $5 \mu \mathrm{m} .{ }^{62}$ Briefly, microspheres fitted for pulmonary drug delivery should have a low mass density $\left(<0.4 \mathrm{~g} / \mathrm{cm}^{3}\right.$, aerodynamic diameter of $1-5 \mu \mathrm{m})$ and a large size $(>5 \mu \mathrm{m})$ which allows for a high accumulation of protein particles in the periphery of the lung, thus preventing phagocytic clearance and realizing a controlled release. ${ }^{63,64}$

\section{Other applications}

New fields that microspheres can be applied to have been discovered. Jiang et al built a lotus-leaf-like superhydrophobic surface with a porous microsphere/nanofiber composite film prepared by electrohydrodynamics. ${ }^{65}$ An electrically charged jet of polystyrene/dimethylformamide solution was pumped by a nozzle to a metal plate, and with the evaporation of the solvent, a porous structure formed. In other fields, porous microspheres can be employed for gastric delivery ${ }^{66}$ and high performance lithium ion battery anode materials. ${ }^{67}$

\section{Conclusion}

Porous microspheres have been extensively studied in recent years for their applications in tissue regeneration, pulmonary drug delivery, and separation of substances. The key characteristics are the porous structure, large specific surface area, and low density. Porous microspheres have an excellent absorption capacity compared with traditional microspheres.

However, many problems still exist in the application of porous microspheres. The methods to prepare porous microspheres are not perfect. For example, the methods used with porogens: the removal of porogens not only leads to the diffusion of the encapsulated drugs, but can also be time consuming and incomplete. The porous structure makes a big difference in the absorption and desorption of substances. So the parameters of the pores should be controllable to perform the desired kinetic behavior. Furthermore, the irritation in pulmonary delivery is not easily addressed. 
In future research, universal technologies to control the pore structure, pore size, and porosity should be studied. New porous materials with ideal pore parameters like mesoporous silica will be beneficial to large scale applications.

\section{Acknowledgments}

The study was supported by the Projects of National Science Foundation, People's Republic of China (numbers 81071025 and 81171203), and Projects of the Shanghai Committee of Science and Technology, People's Republic of China (numbers $11 \mathrm{~nm} 0503300,11410708900$, and 12XD1403800). The authors thank the Analytical Center of Shanghai Jiao Tong University for technical support.

\section{Disclosure}

The authors report no conflicts of interest in this work.

\section{References}

1. Cui YN, Li RL, Deng W, Kan CY. Advances in porous polymer particles. Polymer Materials Science and Engineering. 2008;24(8):1-8.

2. Crotts G, Park TG. Preparation of porous and nonporous biodegradable polymeric hollow microspheres. J Control Release. 1995; 35(2-3):91-105.

3. Zdravkov B, Čermák JJ, Janků J, Kučerová V, Šefara M. Pore classification in the characterization of porous materials. Central European Journal of Chemistry. 2007;5(2):385-395.

4. Gao SL, Wang YJ, Diao X, Luo G, Dai Y. Effect of pore diameter and cross-linking method on the immobilization efficiency of Candida rugosa lipase in SBA-15. Bioresour Technol. 2010;101(11):3830-3837.

5. Cheng XK, He QJ, Li JQ, Huang Z, Chi R. Control of pore size of the bubble-template porous carbonated hydroxyapatite microsphere by adjustable pressure. Cryst Growth Des. 2009;9(6):2770-2775.

6. Li J, Zhang Y. Porous polymer films with size-tunable surface pores. Chem Mater. 2007;19(10):2581-2584

7. Cao SS, Zhao ZY, Jin X, et al. Unique double-shelled hollow silica microspheres: template-guided self-assembly, tunable pore size, high thermal stability, and their application in removal of neutral red. $J$ Mater Chem. 2011;21:19124-19131.

8. Si TB, Wang YX, Wei W, Lv P, Ma G, Su Z. Effect of acrylic acid weight percentage on the pore size in poly(N-Isopropyl acrylamide-co-acrylic acid) microspheres. React Funct Polym. 2011;71(7):728-735.

9. Yoshizawa H, Maruta M, Ikeda S, Hatate Y, Kitamura Y. Preparation and pore-size control of hydrophilic monodispersed polymer microspheres for size-exclusive separation of biomolecules by the SPG membrane emulsification technique. Colloid Polym Sci. 2004 282(9):965-971.

10. Draghi L, Resta S, Pirozzolo MG, Tanzi MC. Microspheres leaching for scaffold porosity control. J Mater Sci Mater Med. 2005; 16(12):1093-1097.

11. Peng CY, Zhao QH, Gao CY. Sustained delivery of doxorubicin by porous $\mathrm{CaCO}_{3}$ and chitosan/alginate multilayers-coated $\mathrm{CaCO}_{3}$ microparticles. Colloids Surf A Physicochem Eng Asp. 2010;353(2-3): $132-139$.

12. Li ZH, Jia Z, Luan YX, Mu TC. Ionic liquids for synthesis of inorganic nanomaterials. Curr Opin Solid State Mater Sci. 2008;12(1):1-8.

13. Wu C, Wang Z, Zhi Z, Jiang T, Zhang J, Wang S. Development of biodegradable porous starch foam for improving oral delivery of poorly water soluble drugs. Int J Pharm. 2011;403(1-2):162-169.

14. Duncanson WJ, Zieringer M, Wagner O, et al. Microfluidic synthesis of monodispersed porous microspheres with size-tunable pores. Soft Matter. 2012;8:10636-10640.
15. Yang Y, Bajaj N, Xu P, Ohn K, Tsifansky MD, Yeo Y. Development of highly porous large PLGA microparticles for pulmonary drug delivery. Biomaterials. 2009;30(10):1947-1953.

16. Lin HR, Kuo CJ, Yang CY, Shaw SY, Wu YJ. Preparation of macroporous biodegradable PLGA scaffolds for cell attachment with the use of mixed salts as porogen additives. J Biomed Mater Res. 2002; 63(3):271-279.

17. Arnold MM, Gorman EM, Schieber LJ, Munson EJ, Berkland C. NanoCipro encapsulation in monodispersed large porous PLGA microparticles. J Control Release. 2007;121(1-2):100-109.

18. Li J, Chen Y, Mak AF, Tuan RS, Li L, Li Y. A one-step method to fabricate PLLA scaffolds with deposition of bioactive hydroxyapatite and collagen using ice-based microporogens. Acta Biomater. 2010;6(6):2013-2019.

19. Ma Z, Gao C, Gong Y, Shen J. Paraffin spheres as porogen to fabricate poly(L-lactic acid) scaffolds with improved cytocompatibility for cartilage tissue engineering. J Biomed Mater Res B Appl Biomater. 2003;67(1):610-617.

20. Liu QQ, Wang L, Xiao AG. Research progress in macroporous styrenedivinylbenzene co-polymer microspheres. Designed Monomers and Polymers. 2007;10(5):405-423.

21. Takai C, Hotta T, Shiozaki S, Matsumoto S, Fukui T. Key techniques to control porous microsphere morphology in $\mathrm{S} / \mathrm{O} / \mathrm{W}$ emulsion system. Colloids Surf A Physicochem Eng Asp. 2011;373(1-3):152-157.

22. Takai $\mathrm{C}$, Hotta $\mathrm{T}$, Shiozaki $\mathrm{S}$, Boonsongrit $Y$, Abe H. Unique porous microspheres with dense core and a porous layer prepared by a novel S/O/W emulsion technique. Chem Commun (Camb). 2009;(37):5533-5535.

23. Sullivan AP, Kilpatrick PK. The effects of inorganic solid particles on water and crude oil emulsion stability. Ind Eng Chem Res. 2002;41(14):3389-3404.

24. Owen R, Marlow M, Stolnik S. Macroporous surface modified microparticles. Soft Matter. 2008;4:1597-1601.

25. Jayakrishnan J, Thanoo BC. Suspension polymerization of 2-hydroxyethyl methacrylate in the presence of polymeric diluents: A novel route to spherical highly porous beads for biomedical applications. J Biomed Mater Res. 1990;24(7):913-927.

26. Li WH, Stöver HDH. Porous monodisperse poly(divinylbenzene) microspheres by precipitation polymerization. J Polym Sci A Polym Chem. 1998;36(10):1543-1551.

27. Wang RW, Zhang Y, Ma GH, Su ZG. Preparation of uniform poly(glycidyl methacrylate) porous microspheres by membrane emulsification-polymerization technology. J Appl Polym Sci. 2006; 102(5):5018-5027.

28. Yan R, Zhang Y, Wang X, Xu J, Wang D, Zhang W. Synthesis of porous poly(styrene-co-acrylic acid) microspheres through one-step soap-free emulsion polymerization: whys and wherefores. J Colloid Interface Sci. 2012;368(1):220-225.

29. Okubo M, Murakami Y, Fujiwara T. Formation mechanism of anomalous "golf ball-like" composite polymer particles by seeded emulsion polymerization. Colloid Polym Sci. 1996;274(6):520-524.

30. Unsal E, Elmas B, Çamli ST, Tuncel M, Şenel S, Tuncel A. Monodispersed-porous poly(styrene-co-divinylbenzene) beads providing high column efficiency in reversed phase HPLC. J Appl Polym Sci. 2005;95(6):1430-1438.

31. Hosoya K, Fréchet JMJ. Influence of the seed polymer on the chromatographic properties of size monodispersed polymeric sseparation media prepared by a multi-step swelling and polymerization method. J Polym Sci A Polym Chem. 1993;31(8):2129-2141.

32. Ou JN, Wu MH, Chen H. Swelling of oligomeric polystyrene seed particles to prepare porous microspheres using n-hexane as porogen. J Mater Sci Lett. 2001;20(24):2221-2223.

33. Okubo M, Ikegami K, Yamamoto Y. Preparation of micron-size monodispersed polymer microspheres having chloromethyl group. Colloid Polym Sci. 1989;267(3):193-200.

34. Coutinho FMB, Neves MAFS, Dias ML. Porous structure and swelling properties of styrene-divinylbenzene copolymers for size exclusion chromatography. J Appl Polym Sci. 1997;65(7):1257-1262. 
35. Ugelstad J, Kaggerud KH, Hansen FK, Berge A. Absorption of low molecular weight compounds in aqueous dispersions of polymeroligomer particles, (2) a two step swelling process of polymer particles giving an enormous increase in absorption capacity. Die Makromolekulare Chemie. 1979;180(3):737-744.

36. Zohrehvand S. On activated seed swelling technique. Polym Int. 2005;54(8):1191-1195.

37. Okubo M, Shiozaki M, Tsujihiro M, Tsukuda Y. Preparation of micron-size monodispersed polymer particles by seeded polymerization utilizing the dynamic monomer swelling method. Colloid Polymer Sci. 1991;269(3):222-226

38. Paul W, Sharma CP. Development of porous spherical hydroxyapatite granules: application towards protein delivery. J Mater Sci Mater Med. 1999;10(7):383-388.

39. Bibby A, Mercier L. Mercury(II) ion adsorption behavior in thiolfunctionalized mesoporous silica microspheres. Chem Mater. 2002; 14(4):1591-1597.

40. Pang JM, Luan YX, Li FF, Cai X, Li Z. Ionic liquid-assisted synthesis of silica particles and their application in drug release. Mater Lett. 2010;64(22):2509-2512.

41. Zhang Y, Zhi Z, Jiang T, Zhang J, Wang Z, Wang S. Spherical mesoporous silica nanoparticles for loading and release of the poorly watersoluble drug telmisartan. J Control Release. 2010;145(3):257-263.

42. Mandal TK, Bostanian TA, Graves RA, Chapman SR, Idodo TU. Porous biodegradable microparticles for delivery of pentamidine. Eur J Pharm Biopharm. 2001;52(1):91-96.

43. Straub JA, Chickering DE, Church CC, Shah B, Hanlon T, Bernstein H. Porous PLGA microparticles: AI-700, an intravenously administered ultrasound contrast agent for use in echocardiography. $J$ Control Release. 2005;108(1):21-32.

44. Lai JP, Lu XY, Lu CY, Ju HF, He XW. Preparation and evaluation of molecularly imprinted polymeric microspheres by aqueous suspension polymerization for use as a high-performance liquid chromatography stationary phase. Anal Chim Acta. 2001;442(1):105-111.

45. Mayes AG, Mosbach K. Molecularly imprinted polymer beads: suspension polymerization using a liquid perfluorocarbon as the dispersing phase. Anal Chem. 1996;68(21):3769-3774.

46. Baimark Y. Porous microspheres of methoxy poly(ethylene glycol)b-poly(e-caprolactone-co-d,l-lactide) prepared by a melt dispersion method. Polymer. 2009;50(20):4761-4767.

47. Kim TK, Yoon JJ, Lee DS, Park TG. Gas foamed open porous biodegradable polymeric microspheres. Biomaterials. 2006;27(2):152-159.

48. Bellehumeur CT, Bisaria MK, Vlachopoulos J. An experimental study and model assessment of polymer sintering. Polym Eng Sci. 1996;36(17):2198-2207.

49. Wang Y, Shi X, Ren L, Wang C, Wang DA. Porous poly (lactic-coglycolide) microsphere sintered scaffolds for tissue repair applications. Materials Science and Engineering: C. 2009;29(8):2502-2507.

50. Brown JL, Nair LS, Laurencin CT. Solvent/non-solvent sintering: A novel route to create porous microsphere scaffolds for tissue regeneration. J Biomed Mater Res B Appl Biomater. 2008;86(2): 396-406.

51. Kim K, Yeatts A, Dean D, Fisher JP. Stereolithographic bone scaffold design parameters: osteogenic differentiation and signal expression. Tissue Eng Part B Rev. 2010;16(5):523-539.
52. Wu L, Bai S, Sun Y. Development of rigid bidisperse porous microspheres for high-speed protein chromatography. Biotechnol Prog. 2003;19(4):1300-1306.

53. Sun HH, Li XN, Ma GH, Su ZG. Polystyrene-type uniform porous microsphere enables high resolution and low-pressure chromatography of natural products - a case study with Icariin purification. Chromatographia. 2005;61(1-2):9-15.

54. Liapis AI, McCoy MA. Theory of perfusion chromatography. J Chromatogr A. 1992;599(1-2):87-104.

55. Li Y, Gao F, Wei W, Qu JB, Ma GH, Zu WQ. Pore size of macroporous polystyrene microspheres affects lipase immobilization. J Mol Catal B Enzym. 2010;66(1-2):182-189.

56. Wang R, Zhang Y, Ma G, Su Z. Modification of poly(glycidyl methacrylate-divinylbenzene) porous microspheres with polyethylene glycol and their adsorption property of protein. Colloids Surf B Biointerfaces. 2006;51(1):93-99.

57. Ungaro F, De Rosa G, Miro A, Quaglia F, La Rotonda MI. Cyclodextrins in the production of large porous particles: Development of dry powders for the sustained release of insulin to the lungs. Eur J Pharm Sci. 2006;28(5):423-432.

58. Kim HK, Chung HJ, Park TG. Biodegradable polymeric microspheres with "open/closed" pores for sustained release of human growth hormone. J Control Release. 2006;112(2):167-174.

59. Lee PF, Zhang XW, Sun DD, Du J, Leckie JO. Synthesis of bimodal porous structured $\mathrm{TiO}_{2}$ microsphere with high photocatalytic activity for water treatment. Colloids Surf A Physicochem Eng Asp. 2008;324(1-3):202-207.

60. Molvinger K, Quignard F, Brunel D, Boissière M, Devoisselle JM. Porous chitosan-silica hybrid microspheres as a potential catalyst. Chem Mater. 2004;16(17):3367-3372.

61. Agu U, Ugwoke MI, Armand M, Kinget R, Verbeke N. The lung as a route for systemic delivery of therapeutic proteins and peptides. Respir Res. 2001;2(4):198-209.

62. Kwon MJ, Bae JK, Jim JJ, Na K, Lee ES. Long acting porous microparticle for pulmonary protein delivery. Int J Pharm. 2007;333(1-2):5-9.

63. Lee ES, Kwon MJ, Na K, Bae JH. Protein release behavior from porous microparticle with lysozyme/hyaluronate ionic complex. Colloids Surf B Biointerfaces. 2007;55(1):125-130.

64. Edward DA, Hanes J, Caponetti G, et al. Large porous particles for pulmonary drug delivery. Science. 1997;276(5320):1868-1871.

65. Jiang L, Zhao Y, Zhai J. A lotus-leaf-like superhydrophobic surface: a porous microsphere/nanofiber composite film prepared by electrohydrodynamics. Angewandte Chemie. 2004;116(33):4438-4441.

66. Jain SK, Agrawal GP, Jain NK. Evaluation of porous carrier-based floating orlistat microspheres for gastric delivery. AAPS Pharm Sci Tech. 2006;7(4):E54-E62.

67. Wang $\mathrm{H}, \mathrm{Wu} \mathrm{Y}$, Bai Y, et al. The self-assembly of porous microspheres of tin dioxide octahedral nanoparticles for high performance lithium ion battery anode materials. J Mater Chem. 2011;21:10189-10194.

68. Chen SF, Gao F, Wang QB, Su ZG, Ma GH. Double emulsion-templated microspheres with flow-through pores at micrometer scale. Colloid Polym Sci. 2013;291(1):117-126.
International Journal of Nanomedicine

\section{Publish your work in this journal}

The International Journal of Nanomedicine is an international, peerreviewed journal focusing on the application of nanotechnology in diagnostics, therapeutics, and drug delivery systems throughout the biomedical field. This journal is indexed on PubMed Central, MedLine, CAS, SciSearch ${ }^{\circledR}$, Current Contents ${ }^{\circledR} /$ Clinical Medicine,

\section{Dovepress}

Journal Citation Reports/Science Edition, EMBase, Scopus and the Elsevier Bibliographic databases. The manuscript management system is completely online and includes a very quick and fair peer-review system, which is all easy to use. Visit http://www.dovepress.com/ testimonials.php to read real quotes from published authors. 